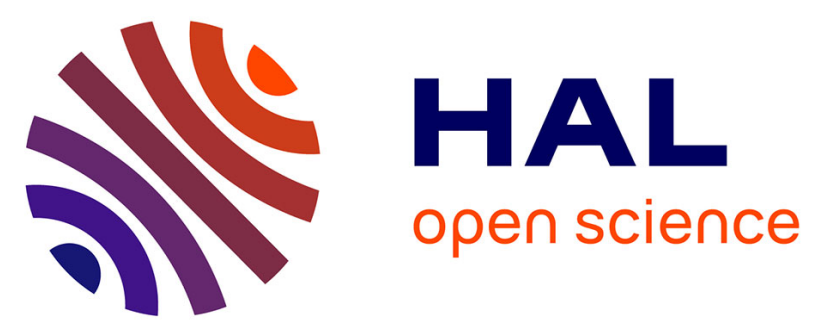

\title{
Voltage Control in Low-Voltage Grids Using Distributed Photovoltaic Converters and Centralized Devices
}

Alessandro Ciocia, Valentin A. Boicea, Gianfranco Chicco, Paolo Di Leo, Andrea Mazza, Enrico Pons, Filippo Spertino, Nouredine Hadj-Said

\section{- To cite this version:}

Alessandro Ciocia, Valentin A. Boicea, Gianfranco Chicco, Paolo Di Leo, Andrea Mazza, et al.. Voltage Control in Low-Voltage Grids Using Distributed Photovoltaic Converters and Centralized Devices. IEEE Transactions on Industry Applications, 2019, 55 (1), pp.225-237. 10.1109/TIA.2018.2869104 . hal-02350955

\section{HAL Id: hal-02350955 \\ https://hal.science/hal-02350955}

Submitted on 19 Oct 2020

HAL is a multi-disciplinary open access archive for the deposit and dissemination of scientific research documents, whether they are published or not. The documents may come from teaching and research institutions in France or abroad, or from public or private research centers.
L'archive ouverte pluridisciplinaire HAL, est destinée au dépôt et à la diffusion de documents scientifiques de niveau recherche, publiés ou non, émanant des établissements d'enseignement et de recherche français ou étrangers, des laboratoires publics ou privés.

\section{(c)(1)}

Distributed under a Creative Commons Attribution| 4.0 International License 


\title{
Voltage Control in Low-Voltage Grids Using Distributed Photovoltaic Converters and Centralized Devices
}

\author{
Alessandro Ciocia ${ }^{(1)}$, Member, IEEE, Valentin A. Boicea, Member, IEEE, Gianfranco Chicco ${ }^{\circledR}$, Fellow, IEEE, \\ Paolo Di Leo ${ }^{\circledR}$, Member, IEEE, Andrea Mazza, Member, IEEE, Enrico Pons ${ }^{(0)}$, Member, IEEE, \\ Filippo Spertino ${ }^{\circledR}$, Senior Member, IEEE, and Nouredine Hadj-Said, Senior Member, IEEE
}

\begin{abstract}
This paper studies the application of distributed and centralized solutions for voltage control in low voltage (LV) grids with high photovoltaic (PV) penetration. In traditional LV grids, the coordination of distributed PV converters and a centralized device would require massive investments in new communication and control infrastructures. The alternative of exploiting distributed PV converters for voltage control is discussed, showing that it can help to stabilize the voltage in the grid connection points also without coordination between them and/or with a centralized unit. The goal of this paper is to investigate how the setup of the voltage controllers inside PV inverters affects the operation of these controllers taking into account the limits for reactive power injection. In addition, the interaction of distributed PV converters with centralized devices (static var compensators and on load tap changers) is analyzed to assess whether additional benefits may come in these cases.
\end{abstract}

Index Terms-Low voltage (LV) grid, on load tap changer (OLTC), Pareto front, photovoltaic (PV) system, reactive power, static var compensator (SVC), voltage regulation.

\section{INTRODUCTION}

$\mathbf{P}$ HOTOVOLTAIC (PV) systems have become one of the most important renewable sources of energy in the world. In addition to environmental advantages due to energy production free from pollutant emissions, also economic returns are achieved with respect to fossil fuels. An accelerated price reduction occurs since the last decades, and during the year 2017, the cost of PV installations decreased below 2 USD/W in

Manuscript received May 22, 2018; revised July 26, 2018; accepted August 29, 2018. Date of publication September 5, 2018; date of current version December 12, 2018. Paper 2018-PSEC-0528.R1, presented at the 2017 IEEE International Conference on Environment and Electrical Engineering and 2017 IEEE Industrial and Commercial Power Systems Europe, Milan, Italy, Jun. 6-9, and approved for publication in the IEEE TRANSACTIONS ON INDUSTRY APPLICATIONS by the Power Systems Engineering Committee of the IEEE Industry Applications Society. (Corresponding author: Alessandro Ciocia.)

A. Ciocia, G. Chicco, P. Di Leo, A. Mazza, E. Pons, and F. Spertino are with the Dipartimento Energia "Galileo Ferraris," Politecnico di Torino, Torino 10129, Italy (e-mail: alessandro.ciocia@polito.it; gianfranco.chicco@ polito.it; paolo.dileo@polito.it; andrea.mazza@polito.it; enrico.pons@polito.it; filippo.spertino@polito.it).

V. A. Boicea is with the Department of Electrical Power Systems, University Politehnica of Bucharest, Bucureşti 060042, Romania (e-mail: boicea@ ieee.org).

N. Hadj-Said is with the G2Elab, Grenoble INP, Grenoble 38402, France (e-mail: nouredine.hadjsaid@g2elab.grenoble-inp.fr).

Color versions of one or more of the figures in this paper are available online at http://ieeexplore.ieee.org. areas with very good solar potential [1]. At the same time, it is estimated that in 2018 the installed PV capacity across Europe will exceed $120 \mathrm{GW}$, while at the global level the PV capacity will approach $370 \mathrm{GW}$ [2].

Small PV systems (e.g., generators installed on the roofs of household buildings) are connected to the low voltage (LV) grid. A high number of distributed generators can cause voltage unbalance, harmonic content increase, and the overheating of the power lines. This happens especially during the periods with low consumption and high production, as in sunny weekends and holidays [3]. Power quality issues related to the PV systems feeding an ac load (considered at the point of common coupling) refer to the harmonic content, frequency and voltage variations, and flicker [4]. In extreme cases, significant fluctuations of these parameters can cause the switch OFF of the PV inverter. When the PV plant is connected to a large-scale distribution system, the current standards concerning fault ride-through capability require that the PV plant remains connected after a fault in the system in which the evolution of the voltage magnitude during time remains within the limits imposed by the standards. In particular, the disconnection of the PV system has to be avoided when the voltage remains inside a given voltage range (e.g., $85 \%-110 \%$ of the rated voltage [5]). An important aspect is the fact that the voltage operating range is set up as a protection function and not as a voltage control function [4]. The typical voltage control band used in normal conditions is $90 \%-110 \%$ of the rated voltage [6].

A possible solution to mitigate voltage control issues in $\mathrm{LV}$ grids could be the implementation of smart grids (SGs) in which there are a coordinated real-time collaboration between centralized devices and distributed converters. Unfortunately, a widespread use of SGs is actually not cost effective, especially due to the large extension of LV grids. An effective coordination would require investments for introducing new communication and control infrastructures [7].

The literature contains a number of papers referring to the impact of large renewable generation capacity and voltage control in the medium voltage (MV) grid [8]. In [9], the potential problems due to large PV generation capacity in MV grids are analyzed: for example, high PV capacity influences power flows, increases voltage variations and affects the dynamic system behavior. To mitigate these problems, in [10], reactive power 
control is preferred to active power curtailment, and the use of different logics for reactive power management is analyzed.

In [11], it is proposed a voltage control method based on continuous voltage monitoring at the MV grid nodes and on reactive power coordination performed by a centralized controller in communication with the PV generators; this solution is compared with the reconfiguration of the MV grid. The results demonstrate the effectiveness of the reactive power management based on real-time control of PV converters. In [12], the voltage of a wind generator is stabilized thanks to the combination of reactive power compensation and the use of an on load tap changer (OLTC). In particular, the reactive power compensation is coordinated with the OLTC and is efficiently used to reduce the number of tap changes. However, the study of voltage control in LV grids with distributed or centralized devices is a recent line of research work. On the centralized voltage control side, possible solutions are the installation of a static var compensator (SVC) at the LV bus in the MV/LV substation, or the installation of a new transformer equipped with an OLTC [8], [13]. These aspects have been addressed in [14], where voltage profiles and losses obtained by controlling voltage with these centralized solutions are compared with another case study, in which distributed PV inverters manage reactive power to adjust voltage in their connection points (CPs). This paper is the extended version of [15], in which the effect of voltage control performed by the combination of the above described centralized and distributed solutions is analyzed.

In the solutions addressed in this paper, there is no data communication between the MV/LV substation and the LV nodes, and all the distributed PV converters are independent of each other in providing voltage control to their CPs.

Three approaches are compared.

1) Only distributed PV converters perform voltage control, thanks to controllers installed inside them, and there is no centralized management. The PV converters continuously check the voltage at their CPs and exchange reactive power to stabilize it.

2) A centralized control is added by simulating the operation of an SVC installed inside the MV/LV substation. The SVC stabilizes the voltage at the LV bus of the transformer. It is assumed that this device does not know the voltages in the other nodes of the LV grid. At the same time, PV converters manage reactive power in order to stabilize voltage in their respective CPs. No information about voltages and reactive power provided by the other distributed converters is used.

3) The SVC is replaced by an OLTC as the centralized device participating in the voltage control.

The current Standards addressing voltage control in LV distribution networks are under rapid evolution. The Italian Standard [5], used as a reference model for reactive power control, defines the voltage band in which the inverters have to work. The identification of these bands could be refined in order to identify different solutions for weak distribution systems (e.g., rural, with the high diffusion of distributed energy resources), or for urban distribution systems in which the voltage typically has smaller variations and the voltage controllability is lower.
The solutions discussed in this paper are not based on the voltage bands defined by the Standards, and determine the voltage bands from the parametric analysis, with the aim to obtain benefits on voltage profiles and provide further hints for upgrading the Standards.

A detailed analysis of the performance of the voltage control devices is carried out by varying their operating parameters. In case of distributed PV converters and SVC, the parameters are the voltage limits for reactive power control and are changed to find how much the reactive power injected into the grid affects the voltage profile. For the OLTC, the parameters (the target voltage and the settings of its integrative regulator) are changed to improve the voltage profile. The three approaches have been applied to two case studies - a real LV grid in Northern Italy, and an IEEE grid in Croatia [16]. In both cases, there are apartments and office loads. Consumption and PV generation profiles are collected from accurate measurements. The simulations are carried out for one week, with one-minute simulation time step.

The next sections of this paper are organized as follows. Section II describes the different types of devices used for voltage control. Section III describes the centralized and distributed voltage control solutions considered in the simulations. Section IV recalls the indicators used to quantify the performance of the voltage control solutions and describes the parametric analysis used to compare the different solutions. Section V includes details about the case studies. Section VI discusses the simulation results. Section VII contains the conclusions.

\section{Voltage Control DeVices}

The classical approaches used in the distribution grids started from the assumption that the voltage decreases from the supply point to the end of the feeder. In that case, voltage control could be made in a centralized way, by acting on the OLTC at the HV/MV substation, or by changing the tap in case a manual tap changer is installed in the MV/LV substation. In the case of large load increase, the solution was left to operational planning solutions, with the substitution of cables or transformers. This kind of approach led to alleviate voltage problems due to the large increase of loads. However, with active distribution networks, this kind of procedure is no longer valid [17].

A modern approach for voltage control in LV grids consists of the use of power electronic devices and OLTC, mimicking the solutions generally used in MV and $\mathrm{HV}$ grids. In some countries, such as Germany, some MV/LV transformers have been replaced with new devices equipped with an OLTC. The effectiveness of these devices in case of high PV penetration is under study [18]. Different works demonstrate the presence of benefits on voltage control [19], [20]. In other cases, it has been established that the increase of renewable hosting capacity is modest or nonexistent [21].

\section{A. OLTC for Voltage Control in LV grids}

The OLTC has several CPs across the high-voltage winding, corresponding to the taps. Each of these taps refers to a certain turns ratio. For a given input voltage, selecting various 
tap positions can vary the output voltage. A controller usually determines the optimal tap position. One of the most important disadvantages of this type of equipment is the occurrence of electric arcs across the primary winding when the tap commutation takes place under load [19]. These arc discharges can cause further degradation of the materials associated with the winding or its insulation, meaning a shorter life of the changer mechanism. As such, the tap must theoretically be changed as seldom as possible.

However, in the operation of the distribution system, sometimes there are dozens of tap variations within a day, especially in those grids with high penetration of renewable energy sources. The operators determine the optimal number of tap changes as a function of voltage and wear of the changer mechanism. The controller that regulates the tap position usually determines the difference between the actual measured voltage at the tap changer and a setup voltage value. When this difference exceeds a certain threshold, a tap changing is carried out. If the voltage measurements are performed in grid nodes different from the installation point of the OLTC, communication systems are necessary. Conversely, without communication systems, the only available voltage measure is located in the MV/LV substation. For example, in [22], a method to estimate voltage profiles and permit an effective control of the OLTC is proposed.

Other problems can occur in grids with high renewable generation penetration. The distributed generation tends to reverse the power flow in the transformer from the end consumer toward the utility grid. Thus, the controller must be capable of keeping the voltage within limits, despite this reversal. That is why, in these cases, a variable set-point is necessary. This setpoint can be either lower or higher, depending on the situation. If the reverse power flow is high, this set-point must be low, and when the power demand of the final customers is high, then the set-point should be high.

\section{B. Power Electronic Devices for Voltage Control in LV Grids}

The main power electronic devices used to carry out voltage control functions are the SVC and the static synchronous compensator [21]. The step voltage regulator (SVR) has been considered in some cases [23]. In this paper, the SVC is used for its simplicity, relatively low cost, and reduced maintenance with respect to the other power solutions with electronics, and the possibility of insertion without upgrading the transformer in the substation as in the case of OLTC.

The SVC is composed of a thyristor-controlled reactor (TCR), a thyristor-switched capacitor (TSC), and an LC filter. The SVC installed in distribution grids performs the functions of mitigating the voltage variations, reducing the absorption of reactive power from the utility network (thus reducing the network losses), balancing the load, and stabilizing the voltage [24]. Automatic voltage control is carried out by the SVC through the calculation of the amount of inductive/capacitive power needed. The difference between the measured voltage and the reference voltage is used to generate the signals to command the thyristors in the SVC. These signals are then converted either in analog signals for imposing the delay angle of the thyristors (in strict dependence with the reactive power demand in the TCR) or in digital signals based on which the thyristors in the TSC are switched ON and OFF.

The other power electronic devices capable of control voltage are PV converters. The simplest case consists of an ON/OFF control: the generator shuts down when the voltage is close to the upper limit (i.e., within a given threshold). An evolution of this method consists of active power curtailment: the active power output is reduced according to the $\mathrm{CP}$ voltage, changing the operation point on the dc current-voltage characteristic curve of the PV generator [25]. The performance of this method increases when there is coordination between all the converters in the feeder: in [26], it is shown the effectiveness of a coordinated active power curtailment control scheme for several PV generators. Another proposed control combines active and reactive power management for voltage control. First, the reactive power available from the converter is varied inside its capability limit; then, if it is not enough, the active power output is reduced [27].

On the contrary, if the active power curtailment is not considered, because the goal is the maximization of renewable energy production, the use of only reactive power management for voltage control is analyzed [28], [29].

\section{Combined Solutions for Voltage Control}

Various solutions for voltage stabilization consisting of different combinations between these types of equipment have been proposed. The coordinated control of distributed energy storage systems proposed in [30] includes OLTC and SVR. The goal is to diminish the stress of the OLTC and the power losses. This method limits, at the same time, the storage depth of discharge in order to improve the life of the batteries. In [31], both active and reactive powers are controlled based on the regulations stipulated in German standards. In [32], the number of tap changes is reduced based on an optimal reactive power coordination achieved through irradiance and load forecast. The so-called runaway condition of the controller, which occurs when the line regulator is operated at its control limit, is taken into account as well. In [33], the voltage in a grid with high PV penetration is controlled using various control strategies of the storage systems. A hybrid voltage/var control method for the same types of grids is proposed in [34]. This method consists of two types of control: coordinated normal control loop and uncoordinated transient cloud movement loop. The first one is based on the scheduling of the hourly dispatches for the capacitor banks, OLTC, and SVCs. This is carried out with the help of load forecasting. The second type of control is adopted when the clouds reduce the irradiance and thus the PV power exhibits significant variations. The goal is to minimize the voltage deviations as well as the power losses. In [35], the voltage in networks with high PV penetration is regulated using an SVR in open-delta connection.

A reactive power flow control for PV inverters in LV distribution networks is proposed in [36]. This is made with the aim of obtaining a robust voltage control by forecasting the reactive power reference in each node and taking into account, at the same time, the influence of the other nodes from the point of view of the reactive power generated or required by 
them. In [37], a remote voltage estimation is made with the goal of renouncing to the monitoring of remote voltages and hence to save money. This procedure determines the number of consumers for each phase and then a generic feeder is created. This is afterward used to forecast the remote voltages based also on substation measurements.

\section{Simulation of Voltage Control Solutions}

\section{A. Voltage Control Performed by Distributed PV Converters}

Distributed PV converters can perform voltage control, in order to stabilize voltage in their respective CPs, without communication with each other or with a centralized unit. In fact, converters have hardware and software capability to perform this task [36], [38]. Generally, the majority of the devices manage reactive power in the same direction, due to external conditions (e.g., a sunny Sunday means high production and low load and leads to a global high voltage). In order to handle this issue, it would be possible to act either on the active power (taking into account the significant resistive nature of the lines) or on the reactive power.

By supposing to avoid the curtailment of the active power generated locally (to maximize the impact of the generation from renewable sources), the voltage control is attempted by managing the reactive power available from the converters inside their capability limits. The reactive power that can be managed by the converters depends on their rated power and on the power flow solution (that takes into account also the effect of the position of the converters in the grid). Thereby, the behavior of each device can change with respect to the general trend. This behavior is intuitively like to a school of fish, in which all the fishes swim together in the same direction, but each of them can move away for food (the same basic idea is used for the particle swarm optimization method [39], [40]). In case of PV converters, each one manages reactive power to stabilize its $\mathrm{CP}$ and can affect voltage in other CPs (making them even worse). This is the limitation of a system without communication between the distributed devices. As described in the next paragraphs, the procedure to simulate the system is developed also to take into account this aspect and evaluate its effects. This kind of control can be based either on Standards (different in every country) or on optimization methods.

For the former approach, as a matter of example, in Italy, the Standard [5] defines how PV converters with rated power higher than $11 \mathrm{kVA}$ have to participate in voltage control. They have to manage reactive power production when the output active power $P_{\text {out }, \mathrm{PV}}$ exceeds $20 \%$ of their rated apparent power $S_{\text {rated,PV }}$ and the voltage lies within suggested ranges $(0.9<V<0.92$ or 1.08 $<V<1.1$ p.u.). When the voltage value falls outside the admitted voltage range (i.e., $0.9-1.1$ p.u.), the converter has to follow other rules defined in the abovementioned standard. Also, the amount of reactive power provided from the inverter is defined in [5]. The correlation between voltage deviation and reactive power control is linear. In the case of an overvoltage, there is no reactive power from the inverter when the voltage magnitude is lower than 1.08, and the inductive power is maximum with $V=1.1$. This correlation is symmetrical in case of $\mathrm{LV}$.

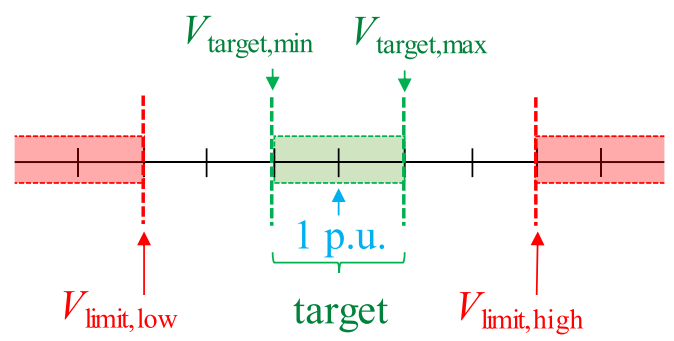

Fig. 1. Voltage ranges and limits of PV converters for reactive power control.

The other solution is to use a hysteresis control with an algorithm to define the minimum value of reactive power, required to adjust voltage. In this paper, the perturb and observe $(\mathrm{P} \& \mathrm{O})$ technique is used: it is a simple calculation procedure that does not require information about the grid and has a low computational cost. In fact, it is widely used to obtain the maximum power point on the dc side of the PV converters [39]. Reactive power is continuously changed by a discrete step. For example, if the consequence of the increase in capacitive reactive power is a consistent decrease in voltage deviation, the procedure continues in the same direction. Otherwise, if the voltage deviation increases, the capacitive reactive power is reduced (which corresponds to the effect of increasing inductive reactive power). The last possible situation corresponds to a relatively low variation in voltage, leading to stop the procedure, to avoid a useless increase in losses. With respect to a traditional $\mathrm{P} \& \mathrm{O}$ technique, the procedure has been slightly modified in order to take into account the effect of external devices, which also work to control voltage. The improvements in the $\mathrm{P} \& \mathrm{O}$ technique are described in detail below and in Sections III-B and III-C.

In [15], it was proposed a procedure essentially based on the satisfaction of the Standard [5], for what concerns the voltage ranges in which converters have to use reactive power. In this paper, a double-band hysteresis control (DBHC) is studied: its limits are varied, in order to find the most suitable setup of the converters to regulate the voltage.

First, the target voltage range $\left(V_{\text {target,min }}-V_{\text {target, } \max }\right)$ is defined as a range around the unity value, which the converters try to reach when reactive power control is activated (see Fig. 1). When the converters are required to keep the voltage as stable as possible, this range is short (e.g., the most stressed and ideal condition is $\left.V_{\text {target,min }}=V_{\text {target,max }}=1\right)$. Hence, the starting points for the voltage control are defined: the PV converters start to manage reactive power when voltages are higher than $V_{\text {limit,high }}$ or lower than $V_{\text {limit,low. Thus, the regions between the }}$ target range and the limits are dead zones. A way to require the PV inverters to work more is to reduce these dead zones. This provides flexibility in the operation of the control system.

Regarding the simulation procedure (see Fig. 2), the first step (STEP\#1) requires the power flow solution with all the loads considered with the PQ model, and also the generators as negative PQ loads. In this way, the voltages are computed in all the nodes of the grid. The second step of the procedure (STEP\#2) uses the voltages calculated at STEP\#1 and the active power injections $P_{\text {out }}$ from the PV generators to identify which PV converters are involved in voltage control. Then, the maximum level 


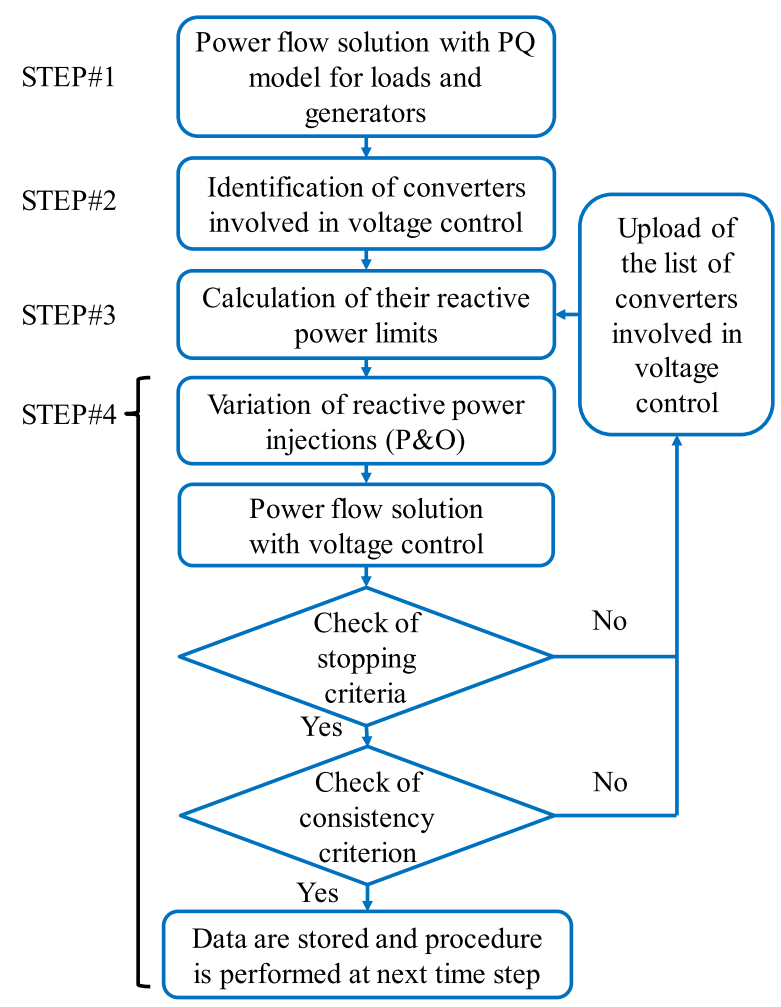

Fig. 2. Procedure to simulate voltage control by distributed PV converters.

of reactive power $Q_{\max , n}(t)$ that the PV system installed in node $n$ can provide is calculated (STEP\#3). According to the Standard [5], a triangular capability curve is respected, so that the power factor $(\mathrm{PF})$ never decreases below the limit $\mathrm{PF}_{\min }=0.9$, as described in [15]. Then, in STEP\#4, the needed amount of reactive power to control voltage is calculated by an algorithm based on the $\mathrm{P} \& \mathrm{O}$ technique. It means that, for each time step, the corresponding subroutine works.

At each iteration of this subroutine, first, the reactive power is varied by a constant amount, then the backward forward sweep (BFS) technique is used to solve the new power flow [41]. For every converter, the reactive power step, which can be managed at each iteration, corresponds to 5\% of its nominal power. The voltages in the CPs of each working converter are compared with the target voltage range. In this way, it is defined if it will be necessary to increase or decrease the reactive power injection during the next step. The procedure stops when one of these criteria is satisfied.

1) The target voltage range is reached in the CPs of the working converter.

2) The reactive power limit of the converter is reached.

This calculation is performed for all the PV converters involved in the voltage control. The list of the PV converters is updated at each iteration because the action of a device could interfere with the operation of the others.

For example, Fig. 3 considers the case of a feeder with two PV generators (GEN\#A and GEN\#B), in which the biggest one is connected at the end of the line (GEN\#B) and exhibits the highest voltage. For this reason, it provides inductive power

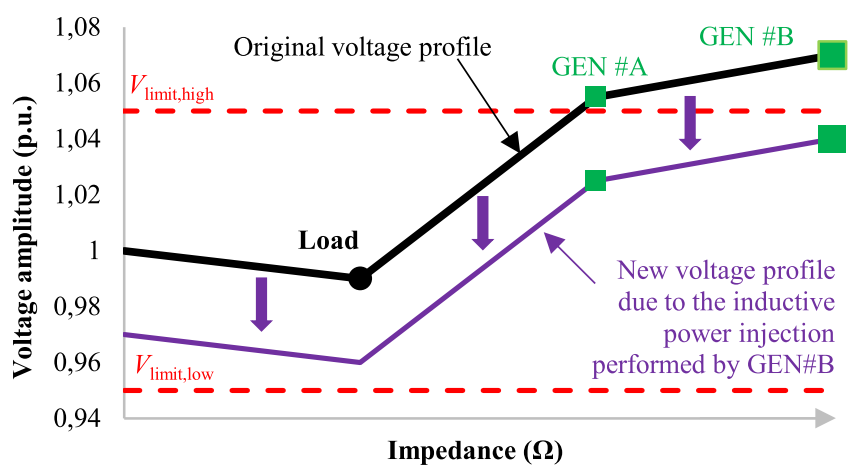

Fig. 3. Interaction between the operation of different PV converters.

and the voltage of the whole feeder decreases. As shown in Fig. 3, in the best case, the operation of GEN\#B could stabilize voltage in the whole feeder such that, at the next iteration, the control from GEN\#A will not be necessary anymore. In other cases, two devices in the same feeder could work in different directions, with the possible incorrect operation of the $\mathrm{P} \& \mathrm{O}$ technique. This issue is typical when there are generators both at the beginning and at the end of the feeders, with loads in the middle. It corresponds also to the case of the interaction of distributed converters and centralized devices (installed in the MV/LV substation). In every case, all the devices have to check a consistency criterion. If the voltage in its $\mathrm{CP}$ is changed due a predominant effect of its reactive power management, the device can continue the voltage control. On the contrary, if the variation on its $\mathrm{CP}$ voltage is due to a predominant effect of other devices in the feeder, another approach has to be used (see Section III-B). Finally, at the end of the subroutine, the contribution of all the converters is defined and the power flow at the next time step is solved.

\section{B. Voltage Control Performed by a Centralized SVC and Distributed PV Converters}

The SVC is installed inside the MV/LV substation. Since there is no communication with other parts of the grid, voltage adjustment by SVC is possible only by measuring the voltage at the LV side of the transformer.

For the simulation of the system with centralized SVC and distributed PV converters, the complete procedure includes the part shown in Fig. 2 for each distributed PV converter, performed in parallel with the one portion shown in Fig. 4 for the centralized voltage control with SVC. The first step (STEP\# $\alpha$ ) consists of the power flow solution as in STEP\#1 of Fig. 2. The voltage is computed in all the nodes of the grid, but only the one corresponding to the LV side of the transformer is used for voltage control. This value is compared with the target voltage range ( $\mathrm{STEP} \# \beta$ ): if an adjustment is needed, then the $\mathrm{P} \& \mathrm{O}$ technique is used in a subroutine to vary the reactive injection $(\mathrm{STEP \#} \gamma)$. At each iteration, the reactive power is varied by a constant amount, defined by the user as a percentage of the nominal power of the device (e.g., 5\%). Then, the BFS technique is used to solve the new power flow. The procedure is repeated 


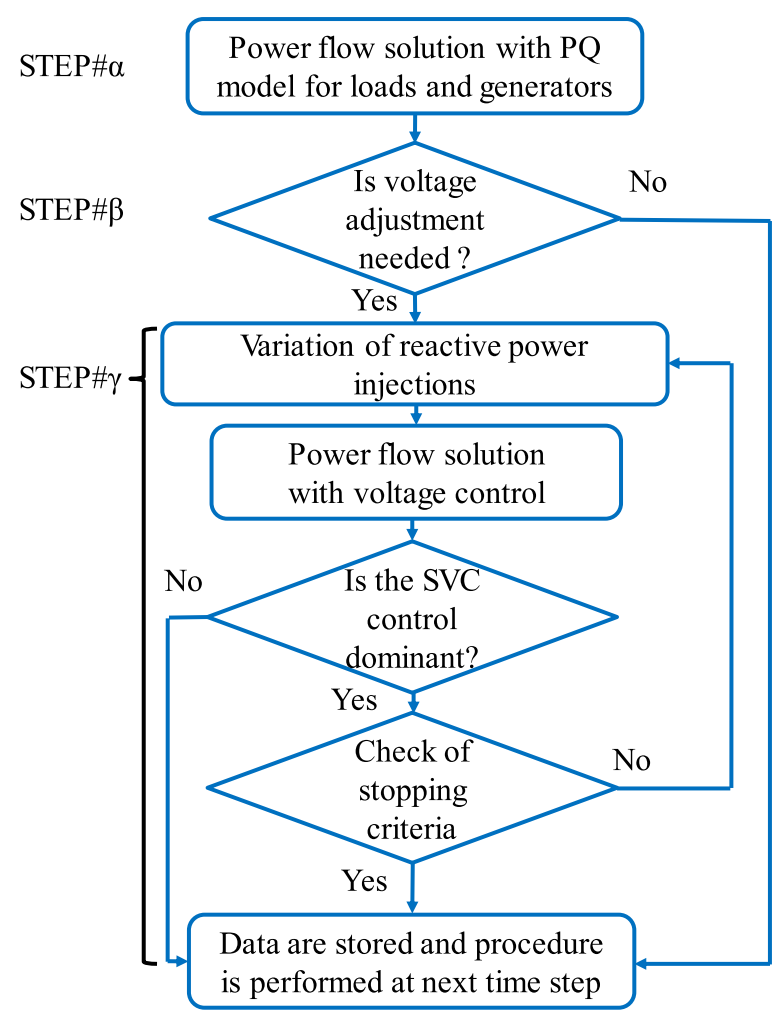

Fig. 4. Procedure for simulation of voltage control by an SVC.

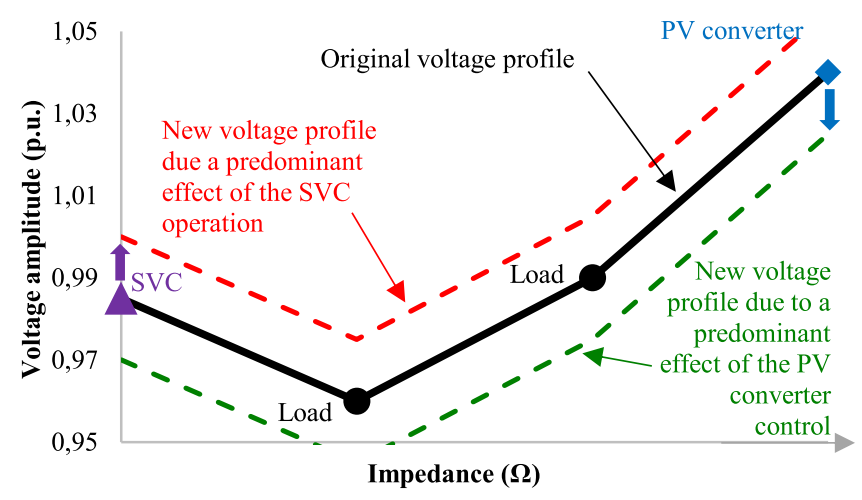

Fig. 5. Example of interaction between SVC and distributed generators.

until either the target voltage range or the limit reactive power values $\left(Q_{\mathrm{SVC}, \min }\right.$ or $\left.Q_{\mathrm{SVC}, \max }\right)$ are reached. Finally, at the end of the procedure, the reactive power injection from the SVC is obtained, and the power flow at the next time step is solved.

With respect to [15], an improvement in the SVC control is present, by introducing a consistency criterion, in order to correctly manage voltage also when the SVC is not the only device controlling the voltage in the feeder. In fact, in this case, the voltage adjustment can depend on the contribution of both the SVC and the PV inverters. Fig. 5 shows an example of the voltage profile of a simplified LV grid. An SVC is installed at the LV bus of the MV/LV transformer and a PV system is connected at the end of the feeder. During sunlight hours, the
PV production increases; thus, the voltage amplitude increases at the end of the feeder. The loads (mainly located in the middle of the line) are supplied in part by local PV generators and in part by the external grid. In this case, the voltages at the CPs of the PV generators are high, and they will increase the inductive reactive power to decrease voltages.

On the other hand, the SVC will try to increase the voltage in the LV bus, up to the reference level (e.g., 1 p.u.). Thanks to $\mathrm{P} \& \mathrm{O}$ techniques, the SVC will try to increase the capacitive reactive power; nevertheless, if $\mathrm{PV}$ generators dominate, the increase of capacitive reactive power could be considered corresponding to the increase of voltage. Consequently, the controller of the SVC will reduce the capacitive reactive power instead of increasing it even more. Thus, to avoid incorrect operations of the SVC, the centralized management has to check if the increase in the use of capacitive reactive power (or a reduction of inductive reactive power) corresponds to an increase in the voltage amplitude. If this is confirmed, the operation of the SVC dominates, and the voltage control can continue in the standard way.

In another case, the variation of the voltage profile is caused by renewable generation and the effect of reactive power injection from the SVC is negligible. In this case, the direction in the variation of reactive power has to be reversed (with respect to the standard $\mathrm{P} \& \mathrm{O}$ ) to avoid additional losses or even increase voltage deviations. In other words, if the voltage is too high, capacitive reactive power is not used. The same check is performed when the SVC increases the injection of inductive reactive power: a reduction in voltage amplitude is expected. If not, PV generators dominate and the SVC is still required to increase the injected inductive reactive power. In this paper, this consistency criterion is used to guarantee the correct operation of all the devices managing reactive power and is fundamental for the control of the SVC.

\section{Voltage Control Performed by an OLTC and Distributed PV Converters}

Regarding the operation of an OLTC, the number of expected daily tap changes is a key point from an economic point of view. In case of a widespread use of OLTCs in LV grids, in order to reduce overall O\&M costs, the number of daily tap changes has to be reduced. In [15], a simplified control of the tap changer was performed: the tap was changed when a considerable voltage deviation was identified. After the change, the device was stopped for a dead time (minutes or hours) to keep low the total number of tap changes. On the contrary, in this paper, in order to better control the number of tap changes, an integrative controller is considered, whose operation is described below.

Regarding the simulation of a system with a centralized OLTC and distributed PV converters, the complete procedure includes the one described in Fig. 2, which operates simultaneously with the voltage control by OLTC. This section describes the part regarding the OLTC control (see Fig. 6). The simulation of the OLTC starts with the power flow solution performed with the pre-existent tap position (STEP\#A). The measured voltage corresponding to the $\mathrm{LV}$ side of the transformer $V_{\mathrm{SVC}}$ is used for 


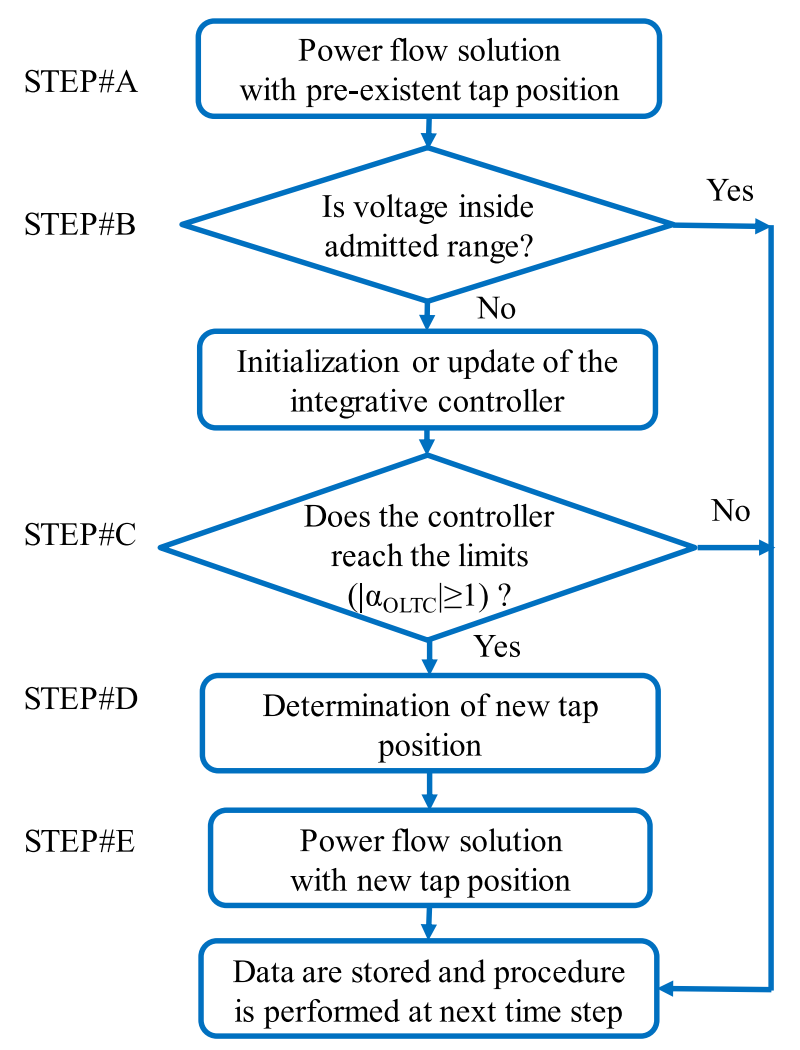

Fig. 6. Procedure for simulation of voltage control by an OLTC.

voltage control in STEP\#B: if it is inside the admitted range, the tap change is not necessary and the simulation continues with the possible voltage control performed by the PV converters. Otherwise, the procedure continues in STEP\#C with the initialization or the upload of the integral control parameter $\alpha_{\text {OLTC }}$. According to [42], this parameter is proportional to the voltage deviation, which is the difference between $V_{\mathrm{SVC}}$ and the reference value $V_{\text {ref. }}$ After each time step $\Delta t$ (e.g., $\Delta t=1 \mathrm{~min}$ ), the parameter $\alpha_{\mathrm{OLTC}}$ is increased of the quantity $\alpha_{\mathrm{OLTC}, \Delta t}$

$$
\alpha_{\mathrm{OLTC}, \Delta t}=\frac{2 \cdot\left(V_{\mathrm{SVC}}-V_{\mathrm{ref}}\right) \cdot \Delta t}{\mathrm{DB} \cdot t_{\mathrm{adm}}} .
$$

The parameter DB is the deadband. In this paper, it is assumed to be equal to half a tap change, $\mathrm{DB}=\Delta V_{\text {tap }} / 2$. If the voltage deviation $\left|V_{\mathrm{SVC}}-V_{\text {ref }}\right|$ is lower than this value, the parameter $\alpha_{\text {OLTC }}$ is not triggered or increased. On the contrary, if the voltage deviation is higher than the deadband, the control parameter $\alpha_{\text {OLTC }}$ is triggered or increased, as shown in the following equation:

$$
\alpha_{\text {OLTC }}(t+1)=\alpha_{\text {OLTC }}(t)+\alpha_{\text {OLTC }, \Delta t}
$$

with $\left|V_{\mathrm{SVC}}-V_{\text {ref }}\right| \geq \mathrm{DB}$.

The parameter $t_{\mathrm{adm}}$ is the main set up of the OLTC; in fact, it approximately establishes the number of tap changes performed during a day. It is the mean time for which a defined voltage violation is allowed. This parameter can be calibrated by rewrit- ing the (1) and using a linear approximation

$$
t_{\mathrm{adm}}=\frac{2 \cdot\left(V_{\mathrm{SVC}}-V_{\mathrm{ref}}\right) \cdot \Delta t}{\mathrm{DB} \cdot \alpha_{\mathrm{OLTC}, \Delta t}} .
$$

For example, the calibration can start by considering the maximum allowed voltage deviation $\left(V_{\mathrm{SVC}}-V_{\text {ref }}=+0.1\right.$ p.u. $)$ and the maximum time for which such violation may exist (e.g., $\Delta t=1 \mathrm{~min})$. Thus, in these conditions, the $\alpha_{\text {OLTC }}$ parameter reaches the limit $\left(\left|\alpha_{\text {OLTC }}\right|=1\right)$. Considering a voltage step of the OLTC of $1.25 \%$, the result is an admitted time $t_{\mathrm{adm}}=32 \mathrm{~min}$. In order to understand which $t_{\text {adm }}$ gives the best compromise between performance in voltage control and maintenance costs of the OLTC, it is necessary to perform simulations with different values of $t_{\mathrm{adm}}$. In this paper, it is selected $t_{\mathrm{adm}}=32 \mathrm{~min}$, because it permits to keep low the number of taps (max 5 per day) reducing the stress on the OLTC.

If the control reaches the limits (i.e., $\left|\alpha_{\text {OLTC }}\right| \geq 1$ ), the tap change is performed by the OLTC. The new position is higher than the previous one if $\alpha_{\text {OLTC }} \leq-1$, and vice versa (tap decrease) in case of overvoltage $\alpha_{\text {OLTC }} \geq+1$. STEP\#E corresponds to the power flow solution performed with the new tap position. If the maximum or the minimum tap position has been already reached, it will not be possible to carry out further tap changes in the same direction.

\section{VOLTAGE INDICATORS AND PARAMETRIC ANALYSIS}

\section{A. Voltage Indicators}

The voltage values calculated in each node of the network are used to evaluate indicators defined for comparing the results of the different voltage control techniques. These indicators have to be defined by taking into account the variability of the data in the time domain. Let us denote with $M$ the total number of timesteps. The following indicators are considered.

1) Voltage deviations with energy flows (VDEF): It counts the sum of the squares of voltage deviations (with respect to a reference value $V_{\text {ref }}$ ) in each node $k$ of the grid and at each time step $t$, multiplied by the energy $E_{k, t}$, in order to give more importance to the nodes and time steps in which the consumption is higher [43]. This sum is divided by the total energy consumed in the entire grid during the simulated time period

$$
\mathrm{VDEF}=\frac{\sum_{t=1}^{M} \sum_{k=1}^{N_{\text {nodes }}}\left(V_{k, t}-V_{\mathrm{ref}}\right)^{2} \cdot E_{k, t}}{\sum_{t=1}^{M} \sum_{k=1}^{N_{\text {nodes }}} E_{k, t}} .
$$

Since VDEF takes into account square values of voltage deviations, it is not possible to distinguish if the deviations are due to overvoltages or undervoltages. To solve this problem, two subindicators are used. Both subindicators are calculated with the formula (4). The first one $\left(\mathrm{VDEF}_{\text {high }}\right)$ includes only the terms $V_{k, t}>V_{\text {ref }}$, while the second one $\left(\mathrm{VDEF}_{\text {low }}\right)$ includes only the terms $V_{k, t}<V_{\text {ref. }}$.

1) The global overvoltage persistence (GOVP): It counts the number of nodes in which the voltage magnitude (at each time step) is higher than the user-defined 
threshold $V_{\text {thres, high }}$

$$
\text { GOVP }=\frac{\sum_{t=1}^{M} \sum_{k=1}^{N_{\text {nodes }}} N_{\left(V>V_{\text {thres,high }}\right)}}{N_{\text {nodes }} \cdot M} .
$$

In the same way, the global undervoltage persistence (GUVP) counts the nodes at every time step at which the voltage magnitude is lower than the threshold $V_{\text {thres,low }}$

$$
\text { GUVP }=\frac{\sum_{t=1}^{M} \sum_{k=1}^{N_{\text {nodes }}} N_{\left(V<V_{\text {thres }, \text { low }}\right)}}{N_{\text {nodes }} \cdot M} .
$$

\section{B. Parametric Analysis}

The goal of the simulations is to define the best setup of distributed and centralized devices to control voltage in the LV feeder. The parameters subject to adjustment of the distributed PV converters are the limits of the DBHC, that is, voltage target range $\left(V_{\text {target,min }}-V_{\text {target,max }}\right)$ and the voltage limits $V_{\text {limit,low }}$ and $V_{\text {limit,high }}$.

In order to be sure to achieve the optimal solution, the abovementioned parameters are changed with discrete steps, and an exhaustive search method is used. In this way, all the possible combinations of the abovementioned parameters are investigated. This method is viable, because the portion of the network considered is an LV feeder, and the parameters are applied in a global way, that is, are the same for all the PV inverters included in the feeder. In this way, the scalability aspects to feeders of different dimensions are solved. Furthermore, this approach is in line with the possible prescriptions that could be established by the Standards (that are applied in a general way and do not depend on the location and size of the PV inverters).

In the example used in this paper, for every parameter, without loss of generality, the discrete variation is 0.01 p.u.; the parameter $V_{\text {limit,low }}$ ranges between 0.9 and 0.97 p.u. ( 8 values), and $V_{\text {target,min }}$ changes in the range $0.95-0.99$ p.u. (5 values). Moreover, the maximum target voltage $V_{\text {target,max }}$ varies between 1.01 and 1.05 p.u. (5 values), and the limit $V_{\text {limit,high }}$ changes between 1.03 and 1.1 p.u. (8 values). On these bases, the total combinations of the four parameters would be $8 \cdot 5 \cdot 5 \cdot 8=1600$, however only the cases that satisfy the condition $V_{\text {limit,low }} \leq V_{\text {target,min }} \leq V_{\text {target,max }} \leq V_{\text {limit,high }}$ are considered, leading to a number of combinations equal to 1156 .

For each combination of parameters, the power flow is computed. The exhaustive search provides the results on the voltage indicators and losses, as indicated in Section VI.

\section{Structure of the Systems Used In the CASe Studies}

\section{A. LV Grids}

The LV grid used in Case\#1 (see Fig. 7) consists of 20 lines and 21 nodes (of which the slack node \#0 is the MV bus of the $\mathrm{MV} / \mathrm{LV}$ substation). The system has grounded neutral and lines with three-pole underground cables, except for the overhead cables in the proximity of the transformer (lines \#L2, \#L3, and \#L4). The position of the PV generators in the grid and the possible connection of an SVC or an OLTC (dashed boxes) is indicated in the figure. In all the lines, the resistive component of the cables prevails over the inductive one. In case of the worst

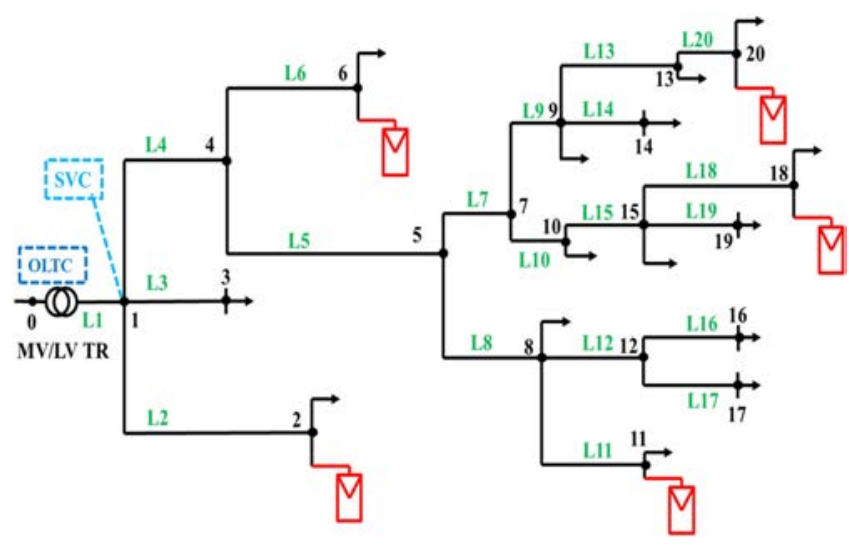

Fig. 7. LV grid under study corresponding to Case \#1.

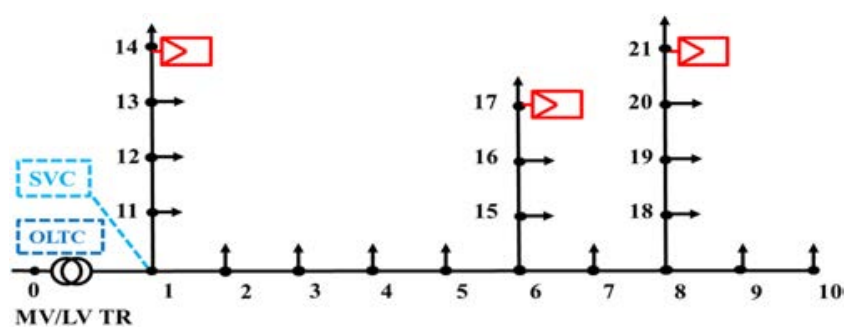

Fig. 8. LV grid under study corresponding to Case \#2.

$\mathrm{CP}$ (node \#18), the total resistance of the lines is $140 \mathrm{~m} \Omega$, while the total reactance is $34 \mathrm{~m} \Omega$ (transformer excluded).

The LV grid used in Case\# 2 consists of 21 lines and 22 nodes (see Fig. 8). The system has grounded neutral and all the lines are three-pole underground cables. In this case, the lines between the worst CP (node \#18) and the LV bus of the transformer have total resistance $156 \mathrm{~m} \Omega$, while their total reactance is $27 \mathrm{~m} \Omega$.

Since the loads in the simulation are considered at the buildings CPs (i.e., each load profile corresponds to the aggregation of different apartments and/or offices), it is assumed that the system is symmetrical and balanced. In this way, the simulation is performed considering an equivalent single-phase model limited only to the positive sequence.

\section{B. Transformers}

The transformers are not equipped with devices for voltage control: the voltage can be seasonally changed by acting on the OFF-load tap changer. In CASE\#1, there is a threephase transformer $20 \mathrm{kV} / 400 \mathrm{~V}$ with rated power $\mathrm{S}_{\text {rated, } t r}=$ $400 \mathrm{kVA}$, nominal current $I_{n}=577 \mathrm{~A}$, short-circuit impedance $Z_{s c} \approx 24 \mathrm{~m} \Omega$, and short circuit power at $75^{\circ} \mathrm{C} P_{S C} 75^{\circ} \mathrm{C}=$ $4.7 \mathrm{~kW}$. In CASE\#2, there is a three-phase transformer $20 \mathrm{kV} / 400 \mathrm{~V}$ with rated power $S_{\text {rated,tr }}=250 \mathrm{kVA}$, nominal current $I_{n}=361 \mathrm{~A}$, short-circuit impedance $Z_{s c} \approx 38 \mathrm{~m} \Omega$, and short-circuit power at $75{ }^{\circ} \mathrm{C} P_{S C_{-} .75^{\circ} \mathrm{C}}=3.4 \mathrm{~kW}$. The transformers are represented with the pi-model, neglecting the iron losses. The series impedance is calculated starting from the transformer datasheets.

In case of installation of an OLTC, it is supposed to replace the transformer with a new one with the same electrical 


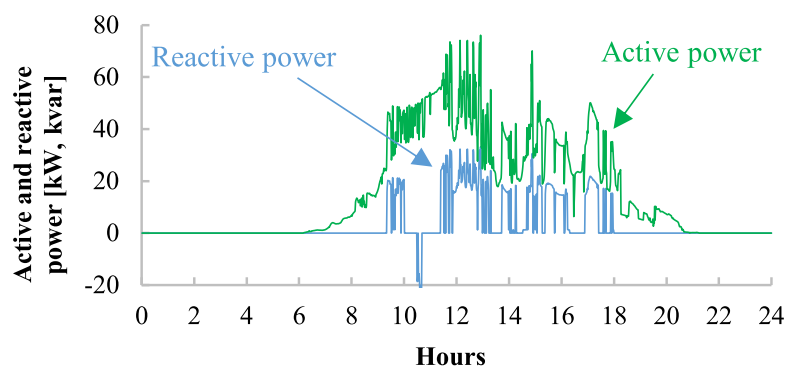

Fig. 9. Daily active and reactive powers from the PV generator in node \#18 (CASE\#1).

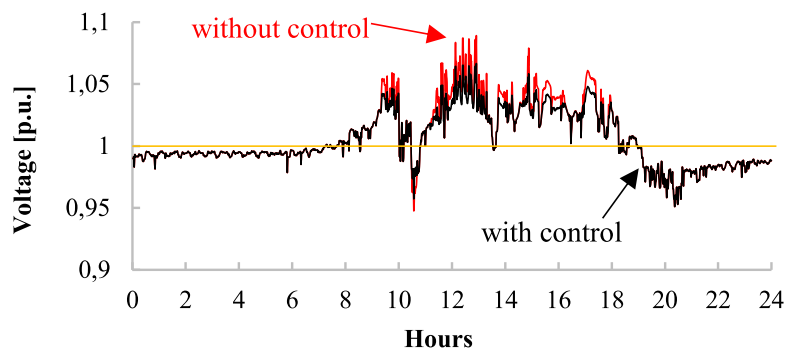

Fig. 10. Daily voltage profile of the PV generator in node \#18 (CASE\#1).

characteristic as the ones described above. The tap changer is characterized by a voltage step of $1.25 \%$ of the nominal value and seven tap positions $(-3, \ldots, 0, \ldots,+3)$ corresponding to a voltage changing in the range $0.9625-1.0375$ p.u. when the transformer is supplied at rated primary voltage.

\section{Load and Generation Profiles}

The consumption patterns have been taken from real values measured on two types of LV loads (apartments and office buildings) with the data acquisition system described in [44]. The generation is composed of PV systems that supply active power variable during the day (taken from real measurements as well), while the reactive power depends on the voltage control as previously indicated.

\section{Simulation Results}

\section{A. Voltage Control by Using Inverters}

The period used in the simulations is one week. The first group of simulations for CASE\#1 is run by assuming that only PV converters are present, and no centralized devices are installed. Fig. 9 shows the power production of the PV generator in the worst node of the feeder (node \#18). During this day, the production profile has high variability and the PV inverter generally injects inductive reactive power to reduce overvoltages. Only in the specific case at 10:30 am, despite PV generation, loads are high and capacitive reactive power is needed to stabilize voltage. Fig. 10 shows the corresponding voltage profile, with values ranging from $V_{\min } \approx 0.95$ to $V_{\max } \approx 1.06$ p.u. during the whole day, while in the reference case without control the voltage range is $0.94-1.08$ p.u. In this case, the voltage control is effective, also in mitigating the effect of the voltage reduction

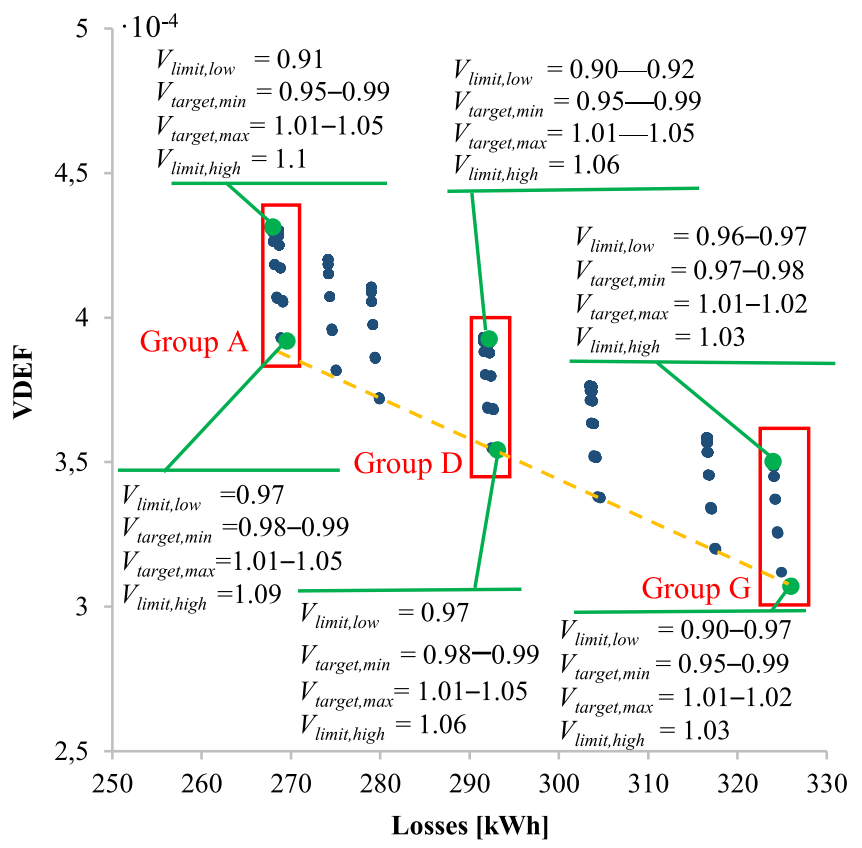

Fig. 11. VDEF-losses chart of the different simulations with only PV converters controlling voltage (CASE\#1).

at a single time step; nevertheless, the voltage control is limited, because it is linked to the active power injection. In fact, the PV inverters cannot work during evening and night, according to [5]; thus, the LV at 8 P.M. corresponds to one of the reference cases without control $\left(V_{\min } \approx 0.95\right.$ p.u. $)$.

Fig. 11 shows the results in case of only PV converters, by plotting the losses with respect to the VDEF parameter. The consequence of different setups is the partitioning into seven groups, each one characterized by solutions with similar losses and different voltages. For example, GROUP\#A includes the solutions with minimum losses $\approx 269 \mathrm{kWh}$. In this group, the minimum VDEF is $3.9 \cdot 10^{-4}$.

Looking at the characteristics of some selected points located in each group at the upper and lower values of VDEF, it appears that the groups are mainly identified by the value of $V_{\text {limit,high }}$, with the particular case of GROUP\#A, in which there are multiple points with the higher values of $V_{\text {limit,high }}$ due to the fact that the losses do not decrease anymore in a significant way when $V_{\text {limit,high }}$ assumes values 1.09-1.1 p.u. Indeed, in the results, there are many combinations of the parameters giving the same pair (VDEF, losses). For this reason, the indications referring to the selected points include in some cases a range of values for the same point. The last group (GROUP\#G) is characterized by losses $\approx 327 \mathrm{kWh}$, which correspond to an increase of $\approx 17 \%$ with respect to GROUP\#A. In GROUP \#A, the minimum $\operatorname{VDEF}\left(3.9 \cdot 10^{-4}\right)$, determines a $20 \%$ increase with respect to the maximum VDEF of GROUP\#G.

From Fig. 11 it is apparent that VDEF and losses can be seen as conflicting objectives inside each group characterized by a given $V_{\text {limit,high }}$. As such, it is possible to exploit a Pareto analysis to identify the nondominated solutions belonging to the Pareto fronts for each group. Overall, the entire picture can be 
TABLE I

RESUltS OF SimUlations With DifFERENT SETUP OF PV CONVERTERS-CASE \# 1 WITH $V_{\text {SLACK }}=1$ p.u.

\begin{tabular}{|c|c|c|c|}
\hline & Group A & Group D & Group G \\
\hline GOVP & $3.3 \cdot 10^{-2}$ & $1.9 \cdot 10^{-2}$ & $\approx 1.1 \cdot 10^{-2}$ \\
\hline$G U V P$ & $(1.1-2.6) \cdot 10^{-3}$ & $(1.1-2.6) \cdot 10^{-3}$ & $(1.1-2.6) \cdot 10^{-3}$ \\
\hline
\end{tabular}

analyzed in the framework of Pareto front analysis. In Fig. 11, the points forming the overall Pareto front are connected with a dashed yellow line. The effects of the different parameters are explained below.

1) $V_{\text {limit,high }}$ : The parameter $V_{\text {limit,high }}$ affects the voltage performance: its decrease corresponds to the increase in losses and the decrease in VDEF. This parameter is the trigger for the voltage control of the inverters: after the start, they try to reach $V_{\text {target,max }}$. Unfortunately, in LV grids, the effect of reactive power is limited; thus, a high reactive power would be necessary to change voltage. It means that many times in which the inverters are required to regulate voltage, they will tend to inject all the available reactive power with resulting high losses, but in many cases, the $V_{\text {target,max }}$ is not reached. As a conclusion, the increasing of $V_{\text {limit,high }}$ means that the inverters act as regulators only when strictly necessary reducing overvoltages only in the worst cases.

2) $V_{\text {target,max }}$ : Another effective way to increase the voltage performance is to decrease $V_{\text {target,max }}$. In every group, it permits to move from the solution with higher VDEF down to the solution with lower VDEF. The decrease of VDEF is lower, with respect to the management of $V_{\text {limit,high }}$, but there is a very small increase in losses. The reason is that inverters are not stressed with the goal of moving close to 1 p.u.; thus, they can be required to regulate multiple times, but with smaller requests.

3) $V_{\text {target,min }}$ and $V_{\text {limit,low: }}$ These parameters do not affect VDEF and losses in these case studies. In fact, inverters are required to regulate mainly when a voltage is high, due to high $\mathrm{PV}$ production. The case, in which production is high but the voltage is low, occurs in a smaller number of situations (e.g., at 10:30 A.M.). Considering the threshold $V_{\text {thres,high }}=1.05$ p.u. in (5) and $V_{\text {thres,low }}=0.95$ p.u. in (6), this aspect is confirmed by the voltage indicator GUVP, which behaves similarly to the parameter VDEF, while the GOVP indicator is quite constant (see Table I). The voltage profile is typically lower than 1 p.u., but the voltages falling below the threshold $V_{\text {thres,low, }}$, are less than the ones exceeding $V_{\text {thres,high }}$. For this reason, GOVP is higher than GUVP.

\section{B. Voltage Control by Varying $V_{\text {slack }}$}

The results presented in Fig. 11 and in Table I refer to a grid with $V_{\text {slack }}=1$ p.u. It is possible to change $V_{\text {slack }}$ by seasonally varying the tap position of the OFF-load tap changer. All the simulations have been repeated by changing $V_{\text {slack }}$ to the values 0.9875 and 1.0125 p.u., corresponding to the

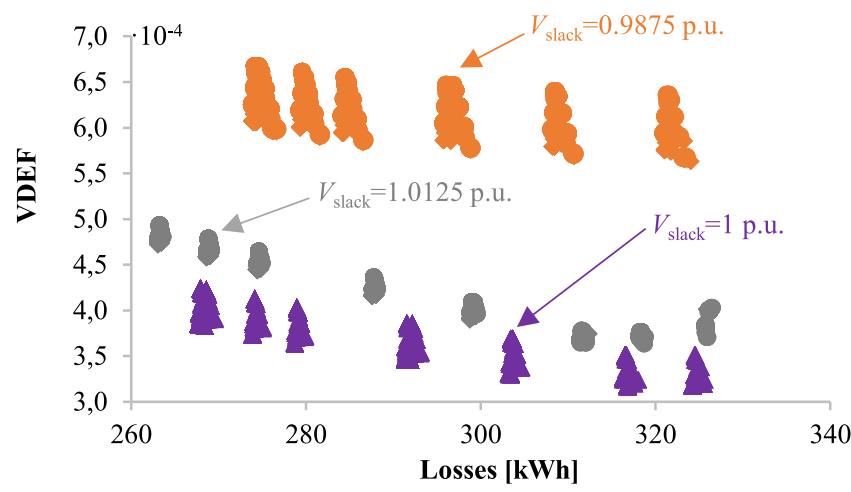

Fig. 12. VDEF-losses chart of the different simulations with OLTC and PV converters controlling voltage (CASE\#1).

TABLE II

MINIMIZATION OF VDEF IN CASE OF ONLY DISTRIBUTED CONVERTERS WITH DIFFERENT $V_{\text {SLACK }}$ - CASE \# 1

\begin{tabular}{|c|c|c|c|}
\hline & $\boldsymbol{V}_{\text {slack }}=\mathbf{0 . 9 8 7 5} \mathbf{p . u}$. & $\boldsymbol{V}_{\text {slack }}=\mathbf{1} \mathbf{p . u .}$ & $\boldsymbol{V}_{\text {slack }}=\mathbf{1 . 0 1 2 5} \mathbf{p . u}$. \\
\hline Losses $[\mathrm{kWh}]$ & 326 & 327 & 332 \\
\hline$V D E F$ & $5.61 \cdot 10^{-4}$ & $3.07 \cdot 10^{-4}$ & $3.15 \cdot 10^{-4}$ \\
\hline$V D E F_{\text {low }}$ & $5.16 \cdot 10^{-4}$ & $2.7 \cdot 10^{-4}$ & $8.53 \cdot 10^{-5}$ \\
\hline$V D E F_{\text {high }}$ & $4.45 \cdot 10^{-5}$ & $1 \cdot 10^{-4}$ & $2.3 \cdot 10^{-4}$ \\
\hline$G O V P$ & $3.32 \cdot 10^{-2}$ & $1.08 \cdot 10^{-2}$ & $2.9 \cdot 10^{-2}$ \\
\hline$G U V P$ & $7.77 \cdot 10^{-3}$ & $1.14 \cdot 10^{-3}$ & $2.83 \cdot 10^{-4}$ \\
\hline
\end{tabular}

tap positions \pm 1 , respectively. Fig. 12 shows the results: with $V_{\text {slack }}=1$, VDEF values are lower. In Table II, only the configurations that minimize VDEF with the same settings $\left(V_{\text {limit,low }}=0.97\right.$ p.u., $V_{\text {target,min }}=0.99$ p.u., $V_{\text {target,max }}=$ 1.01 p.u., and $V_{\text {limithigh }}=1.03$ p.u.) are presented. In the network considered, in the case $V_{\text {slack }}=1$ p.u. the voltages are already relatively low, so that reducing $V_{\text {slack }}$ causes a significant worsening of VDEF, especially for $\mathrm{VDEF}_{\text {low }}$ (see Table II). When $V_{\text {slack }}$ is increased, VDEF increases, because of the overvoltage worsening (higher values of $\mathrm{VDEF}_{\text {high }}$ in Table II). In other terms, if $V_{\text {slack }}=1$ p.u. the ratio $\mathrm{VDEF}_{\text {low }} / \mathrm{VDEF}_{\text {high }}$ is 2.7 , which confirms that during the week undervoltage is the dominant issue. This ratio remains similar when $V_{\text {slack }}=$ 1.0125 p.u. However, if the reference voltage decreases, the voltage performance is strongly affected, as VDEF and $\mathrm{VDEF}_{\text {low }}$ are almost doubled, while $\mathrm{VDEF}_{\text {low }}$ is halved.

\section{Voltage Control by Using Distributed Converters and a Centralized Device}

The results referring to the combination of distributed PV converters and a centralized device are presented in Fig. 13. For every solution, the reference voltage is $V_{\text {slack }}=1$.

In order to reduce the stress on the OLTC, the number of tap changes allowed is kept low (max. 5 per day).

From Fig. 13, it can be seen that the solutions belonging to the overall Pareto front in the case with PV converters and SVC lead to lower (better) VDEF, but higher losses with respect to the case with only PV converters, while in the case with PV converters and OLTC the losses remain almost the same. For more details, 


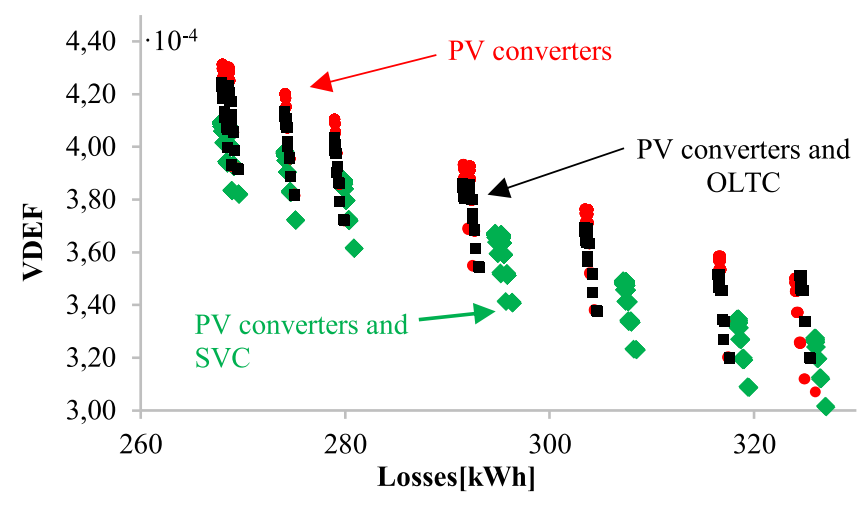

Fig. 13. VDEF-losses chart of the different solutions (only PV converters, OLTC and PV converters, SVC and PV converters (CASE\#1).

TABLE III

MinimizATION OF VDEF WiTH DisTRIBUTED CONVERTERS OR/AND CENTRALIZED DEVICES

\begin{tabular}{|c|c|c|c|c|}
\hline & & $\begin{array}{c}\text { PV } \\
\text { converters }\end{array}$ & $\begin{array}{c}\text { PV } \\
\text { converters } \\
\text { and OLTC }\end{array}$ & $\begin{array}{c}\text { PV } \\
\text { converters } \\
\text { and SVC }\end{array}$ \\
\hline \multirow{2}{*}{ Case \#1 } & Losses $[\mathrm{kWh}]$ & 326 & 325 & 327 \\
\cline { 2 - 5 } & $V D E F$ & $3.07 \cdot 10^{-4}$ & $3.17 \cdot 10^{-4}$ & $3.01 \cdot 10^{-4}$ \\
\hline \multirow{2}{*}{ Case \#2 } & Losses $[\mathrm{kWh}]$ & 193 & 197 & 194 \\
\cline { 2 - 5 } & $V D E F$ & $2.84 \cdot 10^{-4}$ & $2.98 \cdot 10^{-4}$ & $2.65 \cdot 10^{-4}$ \\
\hline
\end{tabular}

the solution with minimum VDEF is the same in the three cases, and corresponds to the values $V_{\text {limit,low }}=0.97$ p.u., $V_{\text {target,min }}=$ 0.99 p.u., $V_{\text {target, } \max }=1.01$ p.u., and $V_{\text {limit,high }}=1.03$ p.u.

In order to further validate the results, Table III shows the values obtained for the two LV grids analyzed. In both cases, power losses variations are negligible, and the best solution to minimize VDEF is the use of a centralized SVC and distributed PV converters. Due to the low number of tap changes allowed per day, the performance of the OLTC device interacting with the PV converters is lower than with the use of the SVC.

\section{CONCLUSION}

The improvement in the technology for distribution network automation is making enhanced solutions for voltage control available. This paper has considered emerging solutions for LV grids, with centralized voltage control from OLTCs or SVCs, together with distributed control from PV converters. The voltage control issue has been analyzed by indicating compromise solutions aimed at reducing an appropriate voltage profile indicator and the network losses, through the identification of the Pareto fronts. The interaction among centralized and distributed voltage control devices has been studied in depth, to understand how voltages and losses change in different configurations. By using distributed PV converters, to inject/absorb reactive power, it is possible to control voltage, because of the operational limits of the PV converters for reactive power provision, together with regulatory barriers that inhibit the use of these converters when there is no active power produced by the PV systems. For each distributed PV converter, a DBHC strategy has been formulated in order to manage the appropriate amount of reactive power provided locally, independently of the other nodes of the grid and in the absence of communication among the nodes or with the centralized control. From the specific cases analyzed, the use of SVC has emerged as a better solution than OLTC for the centralized control coexisting with the local control at the PV converters level. The success of the SVC control depends on its ability to identify when the voltage variation at its grid $\mathrm{CP}$ is due to the SVC operation or to the presence of the distributed PV converters. Furthermore, the SVC may operate in a continuous way. Conversely, the tap changing operation of the OLTC has to be limited to increase the OLTC life and reduce its maintenance, and the timings of the tap changes do not fit well with the voltage variations for $\mathrm{PV}$ production.

\section{REFERENCES}

[1] International Energy Agency, "Trends 2017 in PV applications," 2017, Online. Available at: www.iea-pvps.org/fileadmin/dam/public/report/ statistics/IEA-PVPS_Trends_2017_in_Photovoltaic_Applications.pdf

[2] A. El-Naggar and I. Erlich, "Control approach of three-phase grid connected PV inverters for voltage unbalance mitigation in low-voltage distribution grids," IET Renew. Power Gener, vol. 10, no. 10, pp. 1577-1586, Nov. 2016

[3] B. Nasiri, A. Ahsan, D. M. Gonzalez, C. Wagner, U. Häger, and C. Rehtanz, "Integration of smart grid technologies for voltage regulation in low voltage distribution grids," in Proc. IEEE Innov. Smart Grid Technol. - Asia, Melbourne, VIC, USA, 2016, pp. 954-959.

[4] IEEE Recommended Practice for Utility Interface of Photovoltaic (PV) Systems, IEEE Standard 929-2000, 2000.

[5] Reference Technical Rules for the Connection of Active and Passive Users to the LV Electrical Utilities, CEI Standard 0-21, Dec. 2012. (In Italian).

[6] IEC Standard Voltages, IEC Standard 60038-2009, 2009.

[7] J. Gao, Y. Xiao, J. Liu, W. Liang, and C. L. P. Chen, "A survey of communication/networking in Smart Grids," Future Gener. Comput. Syst., vol. 28, pp. 391-404, 2012.

[8] A. Angioni et al., "A distributed automation architecture for distribution networks, from design to implementation," Sustain. Energy, Grids Netw., [Online]. Available: https://www.sciencedirect.com/science/article/pii/ S2352467716301370?via\%3Dihub

[9] Y. K. Wu, G. T. Ye, and M. Shaaban, "Analysis of impact of integration of large PV generation capacity and optimization of PV capacity: Case studies in Taiwan," IEEE Trans. Ind. Appl.," vol. 52, no. 6, pp. 4535-4548, Nov./Dec. 2016.

[10] S. Pukhrem, M. Conlon, and M. Basu, "Mitigation of over-voltage fluctuation in medium voltage (MV) distribution feeder line with high PV plant penetration," in Proc. 50th Int. Univ. Power Eng. Conf., 2015, pp. $1-5$.

[11] T. T. Ku, C. H. Lin, C. S. Chen, C. T. Hsu, W. L. Hsieh, and S. C. Hsieh, "Coordination of PV inverters to mitigate voltage violation for load transfer between distribution feeders with high penetration of PV installation," IEEE Trans. Ind. Appl., vol. 52, no. 2, pp. 1167-1174, Mar./Apr. 2015.

[12] S. N. Salih and P. Chen, "On coordinated control of OLTC and reactive power compensation for voltage regulation in distribution systems with wind power," IEEE Trans. Power Syst., vol. 31, no. 5, pp. 4026-4035, Sep. 2016.

[13] M. Nijhuis, M. Gibescu, and J. F. G. Cobben, "Incorporation of on-load tap changer transformers in low-voltage network planning," in Proc. IEEE PES. Innov. Smart Grid Technol. Conf. Eur., 2016, pp. 1-6.

[14] D. A. Sarmiento, P. P. Vergara, L. C. P. da Silva, and M. C. de Almeida, "Increasing the PV hosting capacity with OLTC technology and PV VAr absorption in a MV/LV rural Brazilian distribution system," in Proc. 17th Int. Conf. Harmon. Quality Power, 2016, pp. 395-399.

[15] A. Ciocia et al., "Voltage control in low voltage grids: A comparison between the use of distributed photovoltaic converters or centralized devices," in Proc. IEEE Int. Conf. Environ. Elect. Eng./ 2017 IEEE Ind. Commercial Power Syst. Eur., 2017, pp. 1-6.

[16] K. Knezović and S. Krajcar, "Modelling and simulating the impact of a small solar plant to the low-voltage network," in Proc. Eurocon, 2013, pp. 1270-1277.

[17] N. Jenkins, J. B. Ekanayake, and G. Strbac, Distributed Generation, Stevenage, U.K.: Inst. Eng. Technol., 2009. 
[18] W. Heckmann, D. Geibel, T. Degner, and J. Ostergaard, "Application of MV/LV transformers with OLTC for increasing the PV hosting capacity Of LV grids," in Proc. 31 st Eur. Photovoltaic Solar Energy Conf. Exhib., 2015, pp. 1659-1662.

[19] E. M. Baerthlein and A. Panosyan, "System and method for operating an on load tap changer for regulating voltage on an electric power system," U.S. Patent US 9400512 B2, Jul. 26, 2016.

[20] K. Rauma, F. Cadoux, N. Hadj-Saïd, A. Dufournet, C. Baudot, and G. Roupioz, "Assessment of the MV/LV on-load tap changer technology as a way to increase LV hosting capacity for photovoltaic power generators," in Proc. CIRED Workshop, 2016, pp. 1-4.

[21] R. K. Varma, V. Khadikar, and S. A. Rahman, "Utilization of distributed generator inverters as STATCOM.” U.S. Patent US 2012/0205981 A1, Aug. 16, 2012.

[22] A. T. Procopiou and L. F. Ochoa, "Voltage control in pv-rich LV networks without remote monitoring," in Proc. IEEE Power Energy Soc. Gen. Meeting, 2017, pp. 1-10.

[23] Eaton Powering Business Worldwide, "Single-phase step voltage regulators," May 2017, Available at [May 7, 2018]: http://www.cooperindustries. com/content/dam/public/powersystems/resources/library/225_Voltage Regulators/CA225001EN.pdf

[24] M. Eremia, C. C. Liu, and A. A. Edris, "Static VAr Compensator (SVC)," in Advanced Solutions in Power Systems: HVDC, FACTS, and Artificial Intelligence, Hoboken, NJ, USA: Wiley, 2016, pp. 1072-1077.

[25] S. Conti, A. Greco, N. Messina, and S. Raiti, "Local voltage regulation in LV distribution networks with PV distributed generation," in Proc. Int. Symp. Power Electron., Elect. Drives, Automat. Motion, 2006, pp. 519-524.

[26] D. Reeves, G. Nourbakhsh, G. Mokhtari, and A. Ghosh, "A distributed control based coordination scheme of household PV systems for overvoltage prevention," in Proc. IEEE Power Energy Soc. Gen. Meeting, 2013, pp. 1-5.

[27] T. Stetz, F. Marten, and M. Braun, "Improved low voltage grid-integration of photovoltaic systems in Germany," IEEE Trans. Sustain. Energy, vol. 4, no. 2, pp. 534-542, Apr. 2013.

[28] E. Demirok, P. C. González, K. H. B. Frederiksen, D. Sera, P. Rodriguez, and R. Teodorescu, "Local reactive power control methods for overvoltage prevention of distributed solar inverters in low-voltage grids," IEEE J. Photovoltaics, vol. 1, no. 2, pp. 174-182, Oct. 2011.

[29] A. Safayet, P. Fajri, and I. Husain, "Reactive power management for overvoltage prevention at high PV penetration in a low-voltage distribution system," IEEE Trans. Ind. Appl., vol. 53, no. 6, pp. 5786-5794, Nov./Dec. 2017.

[30] X. Liu, A. Aichhorn, L. Liu, and H. Li, "Coordinated control of distributed energy storage system with tap changer transformers for voltage rise mitigation under high photovoltaic penetration," IEEE Trans. Smart Grid, vol. 3, no. 2, pp. 897-906, Jun. 2012.

[31] Y. Bae, T. K. Vu, and R. Y. Kim, "Implemental control strategy for grid stabilization of grid-connected PV system based on german grid code in symmetrical low-to-medium voltage network," IEEE Trans. Energy Convers., vol. 28, no. 3, pp. 619-631, Sep. 2013.

[32] Y. Agalgaonkar, B. C. Pal, and R. A. Jabr, "Distribution voltage control considering the impact of PV generation on tap changers and autonomous regulators," IEEE Trans. Power Syst., vol. 29, no. 1, pp. 182192, Jan. 2014.

[33] J. von Appen, T. Stetz, M. Braun, and A. Schmiegel, "Local voltage control strategies for PV storage systems in distribution grids," IEEE Trans. Smart Grid, vol. 5, no. 2, pp. 1002-1009, Mar. 2014.

[34] Z. Wang, H. Chen, J. Wang, and M. Begovic, "Inverter-less hybrid voltage/var control for distribution circuits with photovoltaic generators," IEEE Trans. Smart Grid, vol. 5, no. 6, pp. 2718-2728, Nov. 2014.

[35] M. I. Hossain, R. Yan, and T. K. Saha, "Investigation of the interaction between step voltage regulators and large-scale photovoltaic systems regarding voltage regulation and unbalance," IET Renew. Power Gener., vol. 10, no. 3, pp. 299-309, 2016.

[36] Á. Molina-García, R. A. Mastromauro, T. García-Sánchez, S. Pugliese, M. Liserre, and S. Stasi, "Reactive power flow control for PV inverters voltage support in LV distribution networks," IEEE Trans. Smart Grid, vol. 8, no. 1, pp. 447-456, Jan. 2017.

[37] A. T. Procopiou and L. F. Ochoa, "Voltage control in PV-rich LV networks without remote monitoring," IEEE Trans. Power Syst., vol. 32, no. 2, pp. 1224-1236, Mar. 2017.

[38] L. Collins and J. K. Ward, "Real and reactive power control of distributed PV inverters for overvoltage prevention and increased renewable generation hosting capacity," Renew. Energy, vol. 81, pp. 464-471, 2015.

[39] J. Kennedy and R. Eberhart, "Particle swarm optimization," in Proc. Proc. IEEE Int. Conf. Neural Netw., 1995, vol. 4, pp. 1942-1948.
[40] A. Mazza, G. Chicco, A. Russo, and E. O. Virjoghe, "Multi-objective distribution network reconfiguration based on pareto front ranking," Intell. Ind. Syst., vol. 2, no. 4, pp. 287-302, 2016.

[41] D. Shirmohammadi, H. W. Hong, A. Semlyen, and G. X. Luo, "A compensation-based power flow method for weakly meshed distribution and transmission networks," IEEE Trans. Power Syst., vol. 3, no. 2, pp. 753-762, May 1988.

[42] M. Hartung, E. M. Baerthlein, and A. Panosyan, "Comparative study of tap changer control algorithms for distribution networks with high penetrations of renewables\%," in Proc. CIRED Workshop, 2014, pp. 1-5.

[43] E. Carpaneto, G. Chicco, M. De Donno, and R. Napoli, "Voltage controllability of distribution systems with local generation sources," in Proc. IREP Symp. Bulk Power Syst. Dyn. Control - VI, 2014, pp. 261-273.

[44] F. Spertino et al., "A power and energy procedure in operating photovoltaic systems to quantify the losses according to the causes," Solar Energy, vol. 118 , pp. 313-326, 2015. 